\title{
Об источниках магм для пород потуданского и павловского комплексов в Волго-Донском орогене (Воронежский кристаллический массив)
}

\author{
Петракова М.Е. ${ }^{1,2}$, Анисимов Р.Л. ${ }^{1}$, Балтыбаев Ш.К. ${ }^{1}$ \\ ${ }^{1}$ ИГГД РАН, Санкт-Петербург, maribya@mail.ru \\ ${ }^{2}$ Воронежский государственный университет, Воронеж
}

Аннотация. Рассмотрены палеопротерозойские гранитоиды известково-щелочной и субщелочной серий павловского и потуданского магматических комплексов близкого возраста (2060-2077 млн. лет). Они имеют разные тренды эволюции состава магм при схожих спектрах распределения REE и близких значениях eNd (до -4). Термодинамическое моделирование FC и AFC-процессов с применением пакета Magma Chamber Simulator на основе петрохимических данных показывает, что для пород павловского комплекса источником магм мог быть протолит с MORB-характеристиками, а для потуданского - с признаками ОIВ. Некоторые особенности трендов эволюции составов могут быть результатом плавления модифицированного материала мантии.

Ключевые слова: Палеопротерозойские гранитоиды, Magma Chamber Simulator, OIB, MORB источник.

\section{Mantle sources of the Pavlovsk and Potudan complexes in the Volgo-Don orogen (Voronezh Crystalline massif)}

\author{
Petrakova M.E. ${ }^{1,2}$, Anisimov R.L. ${ }^{1}$, Baltybaev Sh.K. ${ }^{1}$ \\ ${ }^{1}$ IPGG RAS, Saint-Petersburg, maribya@mail.ru \\ ${ }^{2}$ Voronezh State University, Voronezh
}

Annotation. The Paleoproterozoic granitoids of the calc-alkaline and subalkaline series of the Pavlovsk and Potudan magmatic complexes emplaced closely in time (2060-2077 Ma) are considered. They have different evolution trends of magma composition, despite of their similar REE distribution and eNd characteristics (up to -4). The thermodynamic modeling of FC and AFC processes, using Magma Chamber Simulator package, based on the petrochemical data indicates that mantle source of Pavlovsk granitoid suite affinities to the MORB-type protolith, and a source of Potudan suite correlate with the OIB-type. The specific evolution's trend of compositions can be explained by melting of a modified mantle.

Keywords: Paleoproterozoic granitoids, Magma Chamber Simulator, OIB, MORB, source.

\section{Введение}

Магматические породы павловского и потуданского интрузивных комплексов расположены в Донском террейне Волго-Донского орогена (ДТ ВДО) (рис. 1). Они формировались 2050-2078 млн. лет назад, в постколлизионной обстановке в результате столкновения двух архейский сегментов - Сарматии и Волго-Уралии (Щипанский, 2007; Бибикова и др., 2009; Terentiev at al, 2020).

Породы потуданского комплекса дифференцированы от кварцевого монцогаббро до гранодиорита ( $\mathrm{SiO}_{2}-51-63$ мас. \%), а павловского - от кварцевого монцогаббродиорита до гранита $\left(\mathrm{SiO}_{2}-56-77\right.$ мас. \%); характеризуются схожим порядком кристаллизации минералов (Петракова и Терентьев, 2018).

Все породы являются метаглиноземистыми, относятся к известково-щелочной, щелочноизвесткой серии, обогащены LILE, имеют схожие eNd (до - 4) (Terentiev at al, 2020; Петракова и др., 2020). Некоторые различия пород в том, что потуданские являются железистыми, субщелочными, в отличие от павловских - магнезиальных и известково-щелочных. Эта особенность выражается в разных трендах эволюции павловской и потуданской магм (рис. 2, а).

Несмотря на геологическую, геохимическую и изотопно-геохимическую изученность пород двух комплексов, неясным остается вопрос о возможных источниках их магм. Предполагается, что источниками могли послужить: 1) метасоматизированная мантия; 2) литосферная мантия, контаминированная продуктами верхней коры; 3) примитивная мантия с характеристиками ОIВ (Щипанский и др., 2007; Terentiev et al., 2016; Terentiev at al, 2020). 


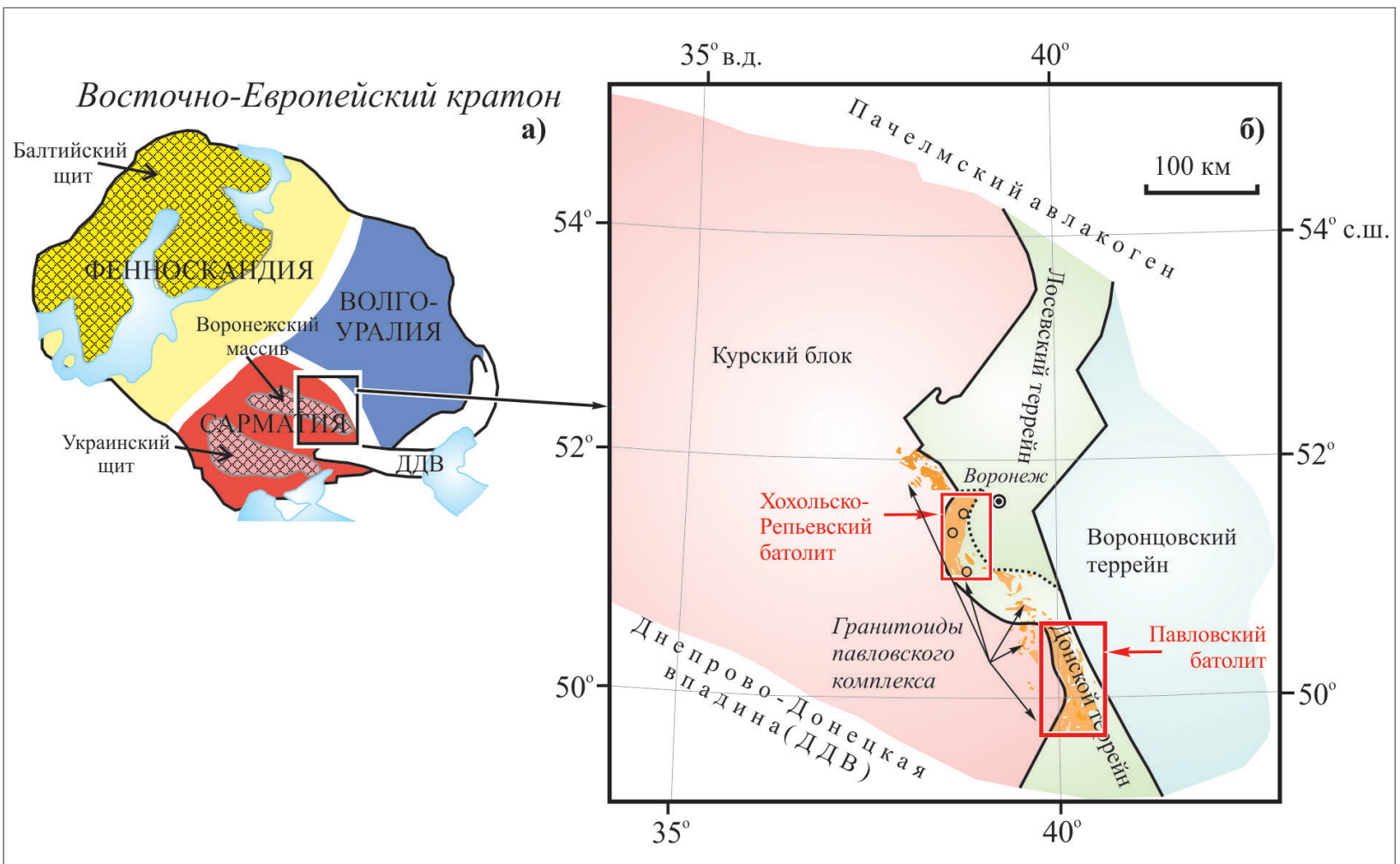

Рис. 1. а) Схема расположения Воронежского кристаллического массива (ВКМ) в пределах ВосточноЕвропейского кратона, б) Схема районирования докембрийского фундамента ВКМ, кроме павловского комплекса, черными кружочками показаны породы потуданского комплекса в ХРБ (вне масштаба).

Fig. 1. a) Schematic map of the Voronezh Crystalline Massif (VCM) in the East-European Craton, b) A structural scheme of the Precambrian basement of the VCM, the rocks of the Pavlovsk complex are shown and rocks of Potudan complex are pointed by black circles in HRB suite (not in scale).

В связи с альтернативным и дискуссионным характером этих предположений, на что указывают и сами вышеперечисленные авторы, мы попытались подойти к определению возможных родоначальных расплавов для двух комплексов, используя термодинамическое моделирование фракционной кристаллизации (FC) с возможной ассимиляцией боковых пород (AFC) для ряда гипотетических составов расплавов. Для этой цели применили пакет Magma Chamber Simulator (MCS), который реализует алгоритм расчета, применяемый в MELTS (Ghiorso, Sack, 1995; Asimov, Ghiorso, 1998).

\section{Краткая геологическая характеристика изученных пород}

Коллизия Сарматского и Волго-Уральского сегментов (рис. 1 а) привела к масштабной магматической активности и формированию гранитоидов павловского комплекса - самого распространенного в регионе. Он представлен двумя крупными батолитами Павловским и Хохольско-Репьевским ( 2000 км² каждый), на юге и севере ДТ ВДО и серией разобщенных массивов в центральной части ДТ и в архейском блоке Сарматии (рис. 1 б). Потуданский комплекс представлен штоками неболь-

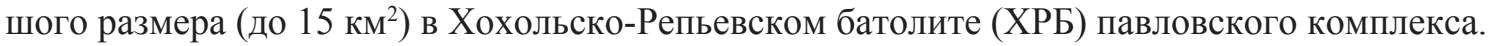

Павловский и потуданский комплексы сопряжены в пространстве и имеют практически идентичный U-Pb возраст по циркон: $2061 \pm 5$ млн. лет для потуданских гранитоидов (Петракова и др., $2020)$ и $2077 \pm 3$ млн. лет для павловских (Бибикова и др., 2009; Terentiev et al., 2020), что подтверждает их принадлежность к одному тектоно-магматическому событию.

\section{Геохимическая и изотопно-геохимическая характеристика пород}

Для пород характерен низкорадиогенный изотопный состав $\mathrm{Nd}$. Для гранитоидов павловского комплекса $\varepsilon \mathrm{Nd}$ от 0.3 до - 4.2, $\mathrm{TNd}\left(\mathrm{DM}_{1}\right)=2.4-2.7$ млрд. лет (Terentiev at al, 2020). Для кварцевых монцогаббро-диоритов плутона Потудань $\varepsilon \mathrm{Nd}$ от -1.7 до -3.7, a $\mathrm{TNd}\left(\mathrm{DM}_{2}\right)=2.6-2.8$ млрд. лет 

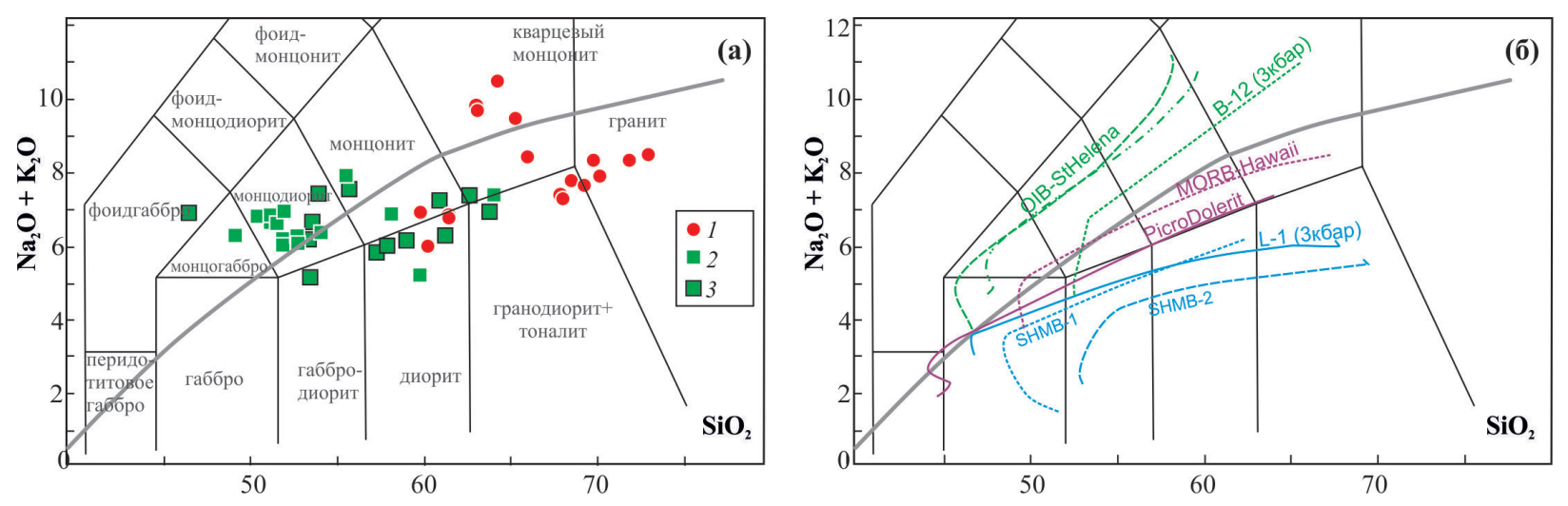

Рис. 2. а) TAS- диаграмма (Midllemost, 1984) для пород павловского и потуданского комплексов, цифрами на рисунке показаны: 1 - павловские гранитоиды, 2 - породы плутона Потудань, 3 - сателлиты потуданского комплекса в ХРБ; б) эволюционные тренды гипотетических источников, характеристика которых дана в тексте.

Fig. 2. a) TAS-diagram (Midllemost, 1984) for rocks of potudan and pavlovsk complex, the figures in the diagram: 1 - Pavlovsk type of granitoids, 2 - Potudan pluton rocks, 3 - satellite of potudan complex in HRB; b) the evolution's trends of the hypothetical sources, which are described in the text .

$\left(\mathrm{TNd}\left(\mathrm{DM}_{1}\right)=2.7\right.$ млрд. лет). Рассчитанные модельные возрасты по $\mathrm{Nd}$ на 700-800 млн лет древнее $\mathrm{U}-\mathrm{Pb}$ возраста цирконов из этих пород и свидетельствуют об общности их источника, имевшего коровую предысторию.

Спектры распределения REE в породах обоих комплексов демонстрируют сильное обогащение LREE относительно HREE и LILE относительно HFSE, сопровождаемое отрицательными аномалиями $\mathrm{Eu}, \mathrm{Nb}$ и $\mathrm{Sr}$. Это означает, что в процессе становления массивов существенную роль сыграла фракционная кристаллизация из LILE обогащенного расплава, при этом роль коровой контаминации оказалась незначительной.

\section{Моделирование FC и AFC процессов и критерии отбора образцов для расчета}

Термодинамическое моделирование выполнено с применением программы MCS (Bohrson et al., 2014), которая позволяет изучить FC и AFC процессы в многокомпонентно-многофазной системе на основе расчетного ядра «семейства» MELTS (Ghiorso, Sack, 1995; Asimov, Ghiorso, 1998). На основе минимизации свободной энергии Гиббса расчеты выявляют порядок кристаллизации минералов из расплава, их пропорции, составы с учетом изменяющихся $P-T$ параметров и разных кислородных буферов. Для нашего исследования выбрана версия rhyolite-MELTS 1.1.0, оптимизированная для высококремнистых составов с присутствием кварца, двух полевых шпатов и $\mathrm{H}_{2} \mathrm{O}$.

Для моделирования FC процесса подбирались параметры близкие к рассчитанным по геотермобарометрам сосуществующих минералов. Температуры ликвидуса подбирались с учетом рассчитанных по Cpx-melt геотермометру (Putirka, 2008): $1200^{\circ} \mathrm{C}$, давление при кристаллизации массивов выбрано 3 кбар по «Al-in-Amf» геобарометру (Anderson, Smith, 1995), для более ранней эволюции расплава 6 кбар. Фугитивность системы QFM определена на основе результатов ильменит-магнетитового фугометра (для потуданских пород) по (Anderson, Lindsley, 1985). Содержания воды в системе оценивалось методом подбора для достижения наилучшего совпадения природных и расчетных трендов, ассоциаций и составов минералов. Для этого были протестированы варианты с содержанием $\mathrm{H}_{2} \mathrm{O}$ от 0.5 до $6 \%$.

Рассматривались следующие альтернативные источники магм: (1) источник с возможным составом лосевских вулканитов; (2) источник с возможным составом вулканитов Байгоровского ареала; (3) источник с возможным составом SHMB (высококремнистые, высокомагнезиальные базальты); (4) источник MORB-типа; (5) источник OIB-типа. Их составы представлены в таблице 1.

Вулканит Лосевского террейна взят с учетом предшествующих исследований (Терентьев и Савко, 2017). Выбранный толеитовый базальт 0182/725 (L-1) имееет самые низкие содержания 
$\mathrm{SiO}_{2}$, высокие содержания щелочей и железа, U-Pb возраст $2120 \pm 9$ млн. лет, eNd $+2.7-+3.6$ и $\mathrm{T}(\mathrm{DM})=2.2-2.4$ млрд. лет (Terentiev et al., 2017).

Таблица 1. Содержания петрогенных оксидов (мас. \%)

в выбранных гипотетических мантийных источниках.

Table 1. Contents of petrogenic oxides (wt. \%) of selected hypothetical mantle sources.

\begin{tabular}{|c|c|c|c|c|c|c|c|c|}
\hline \multirow{2}{*}{ Оксиды } & \multicolumn{2}{|c|}{$\begin{array}{c}\text { Вулканиты Лосевского } \\
\text { террейна }\end{array}$} & \multicolumn{2}{|c|}{ Пилбара } & \multicolumn{2}{|c|}{$\begin{array}{l}\text { Базальты } \\
\text { ОIВ-типа }\end{array}$} & \multicolumn{2}{|c|}{$\begin{array}{c}\text { Базальты } \\
\text { MORB-типа }\end{array}$} \\
\hline & L-1 & Б-12 & SHMB-1 & SHMB-2 & St. Helena & Gough & $\begin{array}{l}\text { Picro- } \\
\text { dolerit }\end{array}$ & Hawaii \\
\hline $\mathrm{SiO}_{2}$ & 43.70 & 51.15 & 51.48 & 53.08 & 45.5 & 47.73 & 44.93 & 49.59 \\
\hline $\mathrm{TiO}_{2}$ & 1.86 & 0.63 & 0.39 & 0.63 & 2.8 & 3.3 & 1.02 & 2.11 \\
\hline $\mathrm{Al}_{2} \mathrm{O}_{3}$ & 13.90 & 17.6 & 9.93 & 12.88 & 13.54 & 15.53 & 13.77 & 14.21 \\
\hline $\mathrm{Fe}_{2} \mathrm{O}_{3}$ (общ) & 18.0 & 10.2 & 10.63 & 10.95 & 11.1 & 10.67 & 1.17 & 4.14 \\
\hline $\mathrm{FeO}$ & & & & 0.18 & & & 13.37 & 8.34 \\
\hline $\mathrm{MnO}$ & 0.287 & 0.128 & 0.23 & 9.64 & 0.11 & 0.14 & 0.23 & 0.19 \\
\hline $\mathrm{MgO}$ & 4.57 & 5.91 & 16.5 & 10.67 & 10.4 & 8.37 & 14.7 & 6.46 \\
\hline $\mathrm{CaO}$ & 8.55 & 7.18 & 9.06 & 1.88 & 10.69 & 8.71 & 8.34 & 9.81 \\
\hline $\mathrm{Na}_{2} \mathrm{O}$ & 2.67 & 3.1 & 0.98 & 0.36 & 2.52 & 2.89 & 1.3 & 2.97 \\
\hline $\mathrm{K}_{2} \mathrm{O}$ & 0.127 & 1.37 & 0.34 & 0.06 & 0.84 & 1.7 & 0.59 & 0.77 \\
\hline $\mathrm{P}_{2} \mathrm{O}_{5}$ & 0.191 & 0.11 & 0.04 & 53.08 & 0.43 & 0.66 & - & 0.56 \\
\hline Источник & $\begin{array}{c}\text { Щипанский } \\
\text { и др., } 2007\end{array}$ & $\begin{array}{l}\text { Tерентьев } \\
\text { и др., } 2016\end{array}$ & \multicolumn{2}{|c|}{ Sun et al.,1989 } & \multicolumn{2}{|c|}{$\begin{array}{c}\text { Sun \& McDonough, } \\
1989\end{array}$} & \multicolumn{2}{|c|}{$\begin{array}{c}\text { Богатиков и др., } \\
1987\end{array}$} \\
\hline
\end{tabular}

Вулканит Байгоровского ареала Лосевского террейна - клинопироксен-плагиоклазовый базальт Б-12/257.5. U-Pb возраст 2047 \pm 17 млн. лет (Terentiev et al., 2016), что отвечает постколлизионному этапу и близко возрасту кристаллизации пород потуданского комплекса. Данный вулканит рассматривается как возможный вулканический аналог потуданских гранитоидов.

$S H M B$, для которых характерно высокие содержания $\mathrm{MgO}$ и $\mathrm{SiO}_{2}$, а также обогащение LREE, $\mathrm{K}, \mathrm{Rb}, \mathrm{Zr}$ и обеднение $\mathrm{Nb}$, Та и $\mathrm{Ti}$, ассоциируются как архейские аналоги бонинитов. Выбран образец 331/337 (SHMB-1) и 331/477 (SHMB-2) из вулканитов архейского кратона Пилбара.

B качестве источника MORB-типа взяты составы образцов с высокими содержания $\mathrm{MgO}$ пикродолерита (Норильск) и базальта (Hawaii) по (Богатиков и др.,1987).

Два состава щелочных базальтов OIB-типа с островов St Helena u Gough с характеристиками eNd около +5 , из обогащенных матийных источников.

Учитывая изотопные $\mathrm{Nd}$ характеристики и модельные возрасты исследуемых образцов ХРБ и то, что породы батолита граничат с архейскими образования Курского блока, в качестве возможного контаминанта (при AFC) был взят состав ТТГ гнейса архейского обоянского комплекса: $\mathrm{SiO}_{2}$ (70.67), $\mathrm{Al}_{2} \mathrm{O}_{3}$ (14.93), $\mathrm{FeO}_{\text {tot }}(3.20), \mathrm{MgO}$ (0.88), $\mathrm{CaO}$ (2.54), $\mathrm{Na}_{2} \mathrm{O}$ (4.39), $\mathrm{K}_{2} \mathrm{O}$ (2.84) по (Щипанский и др., 2007).

\section{Обсуждение результатов моделирования}

Из восьми протестированных нами составов наиболее адекватно воспроизводят тренд реальных составов потуданских пород источники с геохимическими свойствами ОIВ (рис. 2а, б.), сюда же можно отнести вулканит из Байгоровского ареала Лосевского террейна. Для пород павловского комплекса в качестве возможного источника можно рассматривать составы, отвечающие пикродолеритам и базальтам MORB-типа, а также менее щелочной лосевский вулканит (L-1) (рис. 2 б).

Высококремнистые и высокомагнезиальные базальты не воспроизводят тренды пород, характерные для двух рассматриваемых комплексов.

Отрицательные аномалии $\mathrm{Nb}, \mathrm{Ti}, \mathrm{P}$ как в породах потуданского комплекса, так и павловского с одной стороны, и обогащенность LILE и LREE с другой, характерно для субдукционных обста- 
новок (Pearce, 1983). Напротив, невысокие значения $\mathrm{Y} / \mathrm{Nb}$ и $\mathrm{Yb} / \mathrm{Ta}$ в кварцевых монцогаббро-монцодиоритах потуданского комплекса, свидетельствуют о том, что магмы выплавлялись из мантии с OIB геохимическими характеристиками (Eby, 2006). Магнезиальные гранитоиды павловского комплекса сравнивались с архейскими санукитоидами и индийскими Closepet-гранитами (Терентьев и Савко, 2017), для которых предполагается высокомагнезиальный мантийный источник. Для павловских гранитоидов моделирование $\mathrm{Sm}-\mathrm{Nd}$ системы (Терентьев и Савко, 2017) с мантийным источником, отвечающим составу лосевских вулканитов (Щипанский и др., 2007) и коровым компонентом, определенным как средний состав гнейсов донской серии и обоянского комплекса, показало, что магмы павловского комплекса могли образоваться из смешенного корового-мантийного источника.

При моделированнии AFC-процесса существенного изменения в наклоне кривой тренда не выявлено. Это говорит о том, что контаминация расплава породами архейских ТТГ-гнейсов в верхнекоровых условиях не повлияла на эволюцию составов потуданской и павловской магм на ранних этапах кристаллизации.

\section{Выводы}

Посттектонические гранитоиды раннего протерозоя ВДО имеют схожие геохимические характеристики и предполагают участие вещества коры при их генезисе. Возможны несколько источников магм и наиболее вероятными из них могут быть те, которые имеют характеристики ОIВ или MORB. Но не исключается, что первичные расплавы могли иметь составы в разной степени подщелоченной литосферной мантии и эволюция составов расплавов отражает плавление модифицированного материала мантии.

Работа выполнена при поддержке темы НИР ИГГд РАН № FMUW-2019-0003 Минобрнауки России.

\section{Литература}

1. Бибикова Е.В., Богданова С.В., Постников А.В., Попова Л.П., Кирнозова Т.И., Фугзан М.М., Глущенко В.В. Зона сочленения Сарматии и Волго-Уралии: изотопно-геохронологическая характеристика супракрустальных пород и гранитоидов // Стратиграфия. Геол. Корреляция. 2009. Т. 17. № 6. С. 3-16.

2. Богатиков О.А., Косарева Л.В., Шарков Е.В. Средние химические составы магматических горных пород. Справочник. М. Изд-во: Недра. 1987. 153 с.

3. Петракова М.Е., Терентьев Р.А. Петрографические и минералогические признаки взаимодействия гранитоидных и габброидных магм плутона Потудань, Воронежский кристаллический массив // Вестник ВГУ. Серия Геология. 2018. № 1. С. 32-45.

4. Петракова М.Е., Юрченко А.В., Балтыбаев Ш.К., Савко К.А. Геохимические и изотопно-геохимические особенности постколлизионных магматических пород потуданского типа в Восточной Сарматии. // Всероссийская конференция с международным участием, посвященная 90-летию ИГЕМ РАН «Породо-, минерало- и рудообразование: Достижения и перспективы исследований»; 23-27 ноября 2020. ИГЭМ РАН Москва. 2020.

5. Терентьев Р.А., Савко К.А. Минеральная термобарометрия и геохимия палеопротерозойских магнезиально-калиевых гранитоидов Павловского плутона, Восточно-Европейский кратон // Вестник ВГУ. Серия Геология. № 3. 2017. С. 34-45.

6. Терентьев Р.А., Савко К.А., Стрик Ю.Н. Палеопротерозойские андезиты восточной части Воронежского кристаллического массива (Восточно-Сарматский ороген): геохимия и петрогенезис // Вестник ВГУ. Серия Геология. № 1. 2016. С. 66-75.

7. Щипанский А.А., Самсонов А.В., Петрова А.Ю., Ларионова Ю.О. Геодинамика восточной окраины Сарматии в палеопротерозое // Геотектоника. 2007. № 1. С. 43-70.

8. Andersen D.J., Lindsley D.H. New (and final!) models for the Ti-magnetite/ ilmenite geothermometer and oxygen barometer // Abstract AGU, Spring Meeting Eos Transactions. American Geophysical Union 66. V. 18. $1985.416 \mathrm{p}$.

9. Anderson J.L., Smith D.R. The effects of temperature and fO2 on the Al-in-hornblende barometer // Am. Mineral. V. 80. 1995. P. 549-559.

10. Asimow P.D, Ghiorso M.S. Algorithmic Modifications Extending MELTS to Calculate Subsolidus Phase Relations // American Mineralogist V. 83. 1998. P. 1127-1131.

11. Bohrson W.A, Spera F.J, Ghiorso M.S, Brown G.A, Creamer J.B, Mayfield A. Thermodynamic model for 
energy-constrained open-system evolution of crustal magma bodies undergoing simultaneous recharge, assimilation and crystallization: the magma chamber simulator // J Petrol., 55. 2014. P. 1685-1717. https://doi. org/10.1093/petrology/egu036.

12. Eby G.N. Distinctions between A-type granites and petrogenetic pathways Dall'Agnol, R., et al. ed. In: Symposium on Magmatism, Crustal Evolution, and Metallogenesis of the Amozonian Craton, Abstract Volume and Field Trips Guide. Belem. 2006.

13. Ghiorso M.S, Sack R.O. Chemical mass transfer in magmatic processes IV. A revised and internally consistent thermodynamic model for the interpolation and extrapolation of liquid-solid equilibria in magmatic systems at elevated temperatures and pressures // Contrib Mineral Petrol. 119. 1995. P. 197-212. https://doi.org/10.1007/ bf00307281.

14. Middlemost, E.A.K. Naming materials in the magma/igneous rock system. Earth Science Reviews. V. 37. 1994. P. 215-224.

15. Pearce J.A. Role of the Sub-Continental Lithosphere in Magma Genesis at Active Continental Margins. Cheshire, Shiva Publications, Nantwich. 1983. P. 230-249.

16. Putirka K. Thermometers and Barometers for Volcanic Systems / Tepley F. (eds.) // Minerals, Inclusions and Volcanic Processes, Reviews in Mineralogy and Geochemistry, Mineralogical Soc. Am. V. 69. 2008. P. 61-120.

17. Sun S.S., McDonough W.F. Chemical and isotopic systematic of oceanic basalts: implications for mantle composition and processes // Geological Society London Special Publications. 42. 1989. P. 313-345.

18. Sun S.S., Nesbitt R.W., McCulloch M.T. Geochemistry and petrogenesis of Archaean and early Proterozoic siliceous high-magnesian basalts. Boninites and Related Rocks. Unwin Hyman. 1989. P. 148-173.

19. Terentiev R. A., Savko K. A., Santosh M. Paleoproterozoic crustal evolution in the East Sarmatian Orogen: petrology, geochemistry, $\mathrm{Sr}-\mathrm{Nd}$ isotopes and zircon $\mathrm{U}-\mathrm{Pb}$ geochronology of andesites from the Voronezh massif, Western Russia // Lithos. V. 246-247. 2016. P. 61-80.

20. Terentiev R.A., Savko K.A., Santosh M. Paleoproterozoic evolution of the arc-back-arc system in the East Sarmatian Orogen (East European Craton): zircon SHRIMP geochronology and geochemistry of the Losevo Volcanic suite // American Journal of Science. V. 317. 2017. P. 707-753. DOI: 10.2475/06.2017.03.

21. Terentiev R.A., Savko K.A., Petrakova M.E., Santosh M., Korish E.H. Paleoproterozoic granitoids of the Don terrane, East-Sarmatian Orogen: age, magma source and tectonic implications // Precambrian Research. 2020. V. 346. P. 1-24. https://doi.org/10.1016/j.precamres.2020.105790. 